\title{
Bernard Mouralis, Littératures africaines et antiquité. Redire le face-à-face de l'Afrique et de l'Occident
}

\section{Carminella Biondi}

\section{(2) OpenEdition}

1 Journals

\section{Edizione digitale}

URL: https://journals.openedition.org/studifrancesi/4841

DOI: 10.4000/studifrancesi.4841

ISSN: 2421-5856

\section{Editore}

Rosenberg \& Sellier

\section{Edizione cartacea}

Data di pubblicazione: 1 avril 2012

Paginazione: 194

ISSN: 0039-2944

\section{Notizia bibliografica digitale}

Carminella Biondi, «Bernard Mouralis, Littératures africaines et antiquité. Redire le face-à-face de l'Afrique et de l'Occident», Studi Francesi [Online], 166 (I | LVI) | 2012, online dal 30 novembre 2015, consultato il 19 novembre 2021. URL: http://journals.openedition.org/studifrancesi/4841 ; DOI: https://doi.org/ 10.4000/studifrancesi.4841

Questo documento è stato generato automaticamente il 19 novembre 2021.

\section{(c)}

Studi Francesi è distribuita con Licenza Creative Commons Attribuzione - Non commerciale - Non opere derivate 4.0 Internazionale. 


\title{
Bernard Mouralis, Littératures africaines et antiquité. Redire le face-à- face de l'Afrique et de l'occident
}

\author{
Carminella Biondi
}

\section{NOTIZIA}

BERNARD MOURALIS, Littératures africaines et antiquité. Redire le face-à-face de l'Afrique et de l'Occident, Paris, Champion, «Unichamp-Essentiel», 2011, pp. 220.

1 Il nome di Bernard Mouralis, uno dei decani della ricerca sulle letterature africane di lingua francese e sulle relazioni franco-africane, è garanzia della qualità del prodotto. $\mathrm{E}$ il volume che qui presentiamo non delude le aspettative sia per quanto riguarda l'interesse dell'argomento trattato, l'ampiezza e il rigore della trattazione sia, cosa non meno apprezzabile, per la chiarezza dell'esposizione, come richiede, del resto, una collana destinata a studenti, insegnanti, ma anche ad un pubblico di non specialisti. Nella prefazione, l'autore, oltre ad indicare le motivazioni della scelta dell'argomento, spiega l'organizzazione del lavoro e le sue finalità.

2 Il volume è diviso in cinque capitoli: gli ultimi quattro ricostruiscono le varie tipologie di uso, da parte di scrittori e studiosi africani, di quella che l'autore definisce "bibliothèque antique", mentre il primo, intitolato «La bibliothèque antique des écrivains africains» (pp. 19-45), individua e studia il corpus, abbastanza imponente (si tratta di circa un centinaio di opere di varia natura) dei testi antichi che compongono questa "biblioteca". L'autore insiste sul fatto che gli scrittori africani (sia anglofoni che francofoni) «se réfèrent plus souvent qu'on ne pourrait le penser aux auteurs et aux œuvres de l'Antiquité gréco-romaine» (p. 19). Il ricorso, nelle forme più diverse, a questi testi ha motivazioni e finalità molteplici che, per essere lette correttamente, vanno ricollocate «dans le cadre général de cette concurrence des discours qui marque, depuis ses origines, la production littéraire et intellectuelle africaine [...]: l'écrivain 
africain vise moins à "exprimer" une expérience qu'a substituer son propre discours à celui que tient depuis des siècles l'Europe sur l'homme et le monde africain. C'est dans cette perspective éminemment polémique, qu'il convient de situer les usages et les lectures que les écrivains africains font de la bibliothèque antique» (p.15). Uso prevalentemente polemico che, come sottolinea il critico, non esclude né l'erudizione né l'ammirazione. Lo spoglio dei testi del corpus africano scelto ha permesso a Mouralis di individuare quattro grandi poli di interesse, in parte scontati, nell'approccio alla "biblioteca antica": Aristotele, Platone, gli Stoici e i filosofi materialisti, quali Epicuro, Lucrezio..., ma molti altri sono gli autori che la compongono. La tipologia di utilizzazione di queste fonti è ben studiata, come indicano i titoli, nei tre capitoli centrali: «Usages rhétoriques et esthétiques de la bibliothèque antique» (pp. 47-80); «Usages historiques de la bibliothèque antique» (pp. 81-114); «Usages philosophiques de la bibliothèque antique» (pp. 115-64), in cui vengono studiate le diverse modalità di lettura e di appropriazione del testo antico, vale a dire le diverse pratiche intertestuali utilizzate dallo scrittore, dallo storico o dal filosofo africano, in funzione dello scopo che persegue. L'ultimo capitolo, intitolato «Intersections» (pp.165-193), merita un discorso a parte, perché l'autore vi analizza, negli scrittori antichi, alcune tematiche che sono particolarmente vicine al mondo africano, quali "colonizzazione e cittadinanza", "bilinguismo latino/greco presso i Romani", "primitivismo", che "interseca" con tematiche analoghe negli scritti africani, spiegando bene cosa intenda con procedimento di intersezione e, quindi, in cosa consista la differenza tra i tre capitoli centrali e il capitolo conclusivo: «alors que l'intertextualité, en règle générale, renvoie à un travail conscient de l'écrivain sur les textes qui le précèdent ou l'entourent, l'intersection correspond plutôt à un processus de rapprochement qui n'est pas nécessairement voulu ou souhaité par celui-ci, mais qui est susceptible d'éclairer l'œuvre analysée...» (p. 165).

3 Il volume è corredato di una ricca bibliografia e di un indice dei nomi, molto utile per non perdersi nel fitto reticolo di rinvii a fonti primarie e secondarie che caratterizza il saggio. Ritengo che non sia eccessivo definirlo un testo di riferimento obbligato non solo per gli studi sulla cultura africana, almeno quella scritta in lingue europee, ma anche per gli studi sulla permanenza dell'antico nella letteratura contemporanea. 